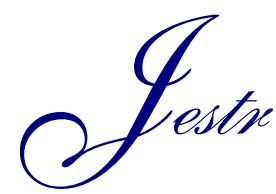

Review Article

www.jestr.org

\title{
A Survey with Emphasis on Adaptive filter, Structure, LMS and NLMS Adaptive Algorithm for Adaptive Noise Cancellation System
}

\author{
Rachana Nagal $^{1, *}$, Pradeep Kumar ${ }^{2}$ and Poonam Bansal ${ }^{3}$ \\ Department of ECE/ICE, Amity School of Engg and Technology, New Delhi-110061
}

Received 30 September 2015; Accepted 12 March 2017

\begin{abstract}
This paper discusses the evolution of adaptive filtering, filter structure, adaptive algorithms used for noise cancellation over the past five decades. The field of adaptive signal processing has been matter of research for over 50-60 years. The major growth occurred in this field in eighties because of the availability of implementation tools and textbooks. Adaptive signal processing has made a significant contribution in the last 50 years. The applications of adaptive signal processing are very appealing because of its properties like low costing, constancy, fidelity, small sizes, and adjustability. This revolutionary change brought along with the problems of noise and the solution is the design of the adaptive filter. This paper mainly focused on adaptive filter, and its structure, the Least Mean Square Algorithm (LMS) and Normalized Least Mean Square Algorithm (NLMS), used for noise cancellation. This paper could serve as a survey for beginners and as a reference to select the related reference of their field.
\end{abstract}

Keywords: Adaptive filter, Adaptive filter Structure, Adaptive Algorithm, Least Mean Square algorithm, Noise Cancellation.

\section{Introduction}

The designing of electronic system must depend upon the different type of noise and distortion. The noise can be added during the process of signal through a channel due to the slow or fast variations of its properties. As most of the time the variations are unknown, so it is adaptive filtering that completely eliminates the signals distortion. So the adaptive system is something whose structure is adjustable as per its performance or behaviour. The main quality of the adaptive model is its time variance and self-adjusting nature. The adaptive filter with adaptive algorithm finds its application in adaptive noise cancellation.

The concept behind adaptive noise cancellation is discussed in the Fig 1 below. An input signal $x(n)$ passes to a sensor that also accepts noise $\mathrm{N}_{\mathrm{o}}(\mathrm{n})$. This noise $\mathrm{N} 0$ (n) is not correlated with the signal. The input signal is mixed with the noise and forms a noise corrupted signal $\{\operatorname{Sig}(\mathrm{n})=$ $\left.\mathrm{x}(\mathrm{n})+\mathrm{N}_{\mathrm{o}}(\mathrm{n})\right\}$ or the noisy signal. There is a second sensor which captures noise $N_{i}(n)$ which is not related with the signal but somehow correlated with the first noise signal $N_{o}(n)$. This gives the reference input to the adaptive noise canceller model. The output $\mathrm{y}(\mathrm{n})$ is produced by filtering the noise $\mathrm{N}_{\mathrm{i}}(\mathrm{n})$ that should be as close as possible to $\mathrm{N}_{\mathrm{o}}(\mathrm{n})$. The generated outputs get subtracted from the noise corrupted signal and produce the required signal $\mathrm{d}(\mathrm{n})=\{\operatorname{Sig}(\mathrm{n})-\mathrm{y}(\mathrm{n})\}$. The adaptive filter is an adequate concept that can be able to adjust its transfer function via an adaptive algorithm. The adaptive algorithm is to minimize the error signal. This error signal is feedback to adaptive

*E-mail address: rachana.nagal@gmail.com

ISSN: 1791-2377 @ 2017 Eastern Macedonia and Thrace Institute of Technology. All rights reserved. filter. The adaptive algorithm now try to minimize this error signal as minimum as possible. This error signal is an important parameter to judge the accuracy of algorithm along with its convergence.

So to design an adaptive noise cancellation system the points listed below needs to be taken care of:

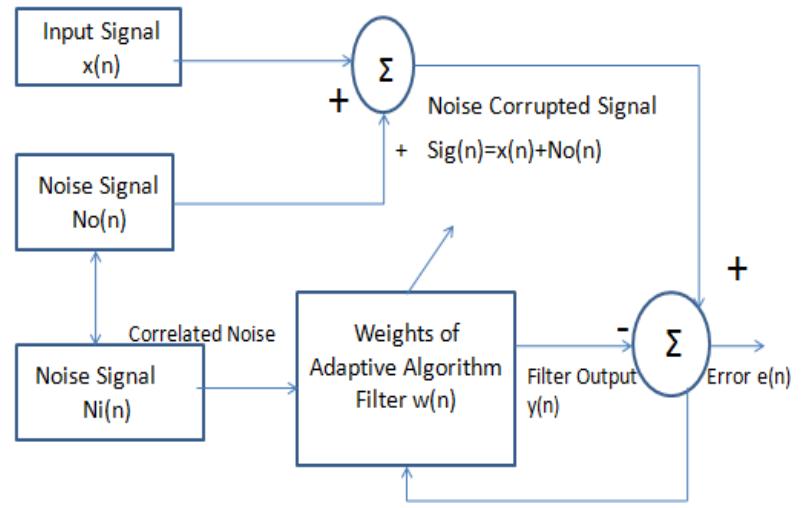

Fig. 1. Basic Concept of Noise Cancellation

1. The input signals which is being treated by the adaptive filter.

2. The structure of the filter that shows the mathematical relation between output and input signal.

3. Parameters inside the structure that can change the input output relationship of the filter.

4. The most important is adaptive algorithm, required to update the parameters of the filter. 
So in this paper we provide the journey of adaptive filter, filter structures, the basic adaptive LMS algorithm and one of its variant i.e. NLMS.

The organization of this paper is as follows: Section 2 gives an overview of adaptive filters; Section 3 discusses the different filters structures. Then in the Section 4 the basic LMS algorithms and its literature will be shown. Further Section 4 discusses the advancement done on one variant of LMS algorithm i.e. NLMS and challenges faced by those algorithms. The last section concludes the journey.

\section{Adaptive filter}

Norbert Wiener [1] pioneered research was focused on designing of adaptive filter. The aim of Wiener was to design a filter, which would produce the least mean square error to measure the desired signal. The designing of the filter was based on the statistical parameters like estimated mean, correlation of output signal and the input noise.

\subsection{FIR Wiener Filter}

By using the Wiener theory, the concept of the adaptive recursive LMS filter was first proposed by B.Widrow and Hoff [2]. The filter designed was Finite Impulse Response (FIR) or non-recursive filter. The drawback of non-recursive filter is, it has a finite impulse response (FIR) and can only realize zeros of a digital filter transfer function. The recursive filter is one which is structurally capable of realising both zeros and poles of digital filter transfer function. It must also have infinite impulse response controlled by adjusting its weighting coefficient. This theory is given and proved by B.Widrow, S.D.Stearns [3] and S.T. Alexnader [4]. They have proved that the most common adaptive filter used during the adaption process is the FIR filters because they are stable and easy to implement. The outcome of FIR Wiener filter is the least mean-square of a given signal $d(n)$. It is assumed that input signal and desired signal are jointly wide-sense stationary with known autocorrelations, $\operatorname{rx}(\mathrm{k})$ and $\operatorname{rd}(\mathrm{k})$, and known cross-correlation $\operatorname{rdx}(\mathrm{k})$. J. R. Treichler, M. Bellanger, S. Haykins, and A. H Sayed[5-8], in their book denoting the unit impulse response of the Wiener filter by $w(n)$, and assuming a (p-1)st-order filter, the system function is

$W(z)=\sum_{n=0}^{p-1} w(n) z^{-n}$

With $\mathrm{x}(\mathrm{n})$ the input signal to the filter, the output signal is denoted by $\hat{d}(n)$, is the convolution of $w(n)$ with $x(n)$,

$\widehat{\mathrm{d}}(\mathrm{n})=\sum_{\mathrm{l}=0}^{\mathrm{p}-1} \mathrm{w}(\mathrm{l}) \mathrm{x}(\mathrm{n}-\mathrm{l})$

The Wiener filter model needs to get the coefficients of the filter $\mathrm{w}(\mathrm{k})$, that reduces the mean-square error

$$
\xi=E\left\{|e(n)|^{2}\right\}==E\left\{|d(n)-\widehat{d}(n)|^{2}\right\}
$$

In order to minimize set of filter coefficients $\xi$, it is necessary and sufficient that if the derivative of $\xi$ with respect to $\mathrm{w}^{*}(\mathrm{k})$ is taken then it should be equal to zero for all positive values $\mathrm{k}$.

$\frac{\partial \xi}{\partial \mathrm{w}^{*}(\mathrm{k})}=\frac{\partial}{\partial \mathrm{w}^{*}(\mathrm{k})} \mathrm{E}\left\{\mathrm{e}(\mathrm{n}) \mathrm{e}^{*}(\mathrm{n})\right\}=\mathrm{E}\left\{\mathrm{e}(\mathrm{n}) \frac{\partial \mathrm{e}^{*}(\mathrm{n})}{\partial \mathrm{w}^{*}(\mathrm{k})}\right\}=0$

With

$e(n)=d(n)-\sum_{l=0}^{p-1} w(l) x(n-l)$

It follows that

$\frac{\partial \mathrm{e}^{*}(\mathrm{n})}{\partial \mathrm{w}^{*}(\mathrm{k})}=-\mathrm{x}^{*}(\mathrm{n}-\mathrm{k})$

So Eq. (2.1.4) become

$\mathrm{E}\left\{\mathrm{e}(\mathrm{n}) \mathrm{x}^{*}(\mathrm{n}-\mathrm{k})\right\}=0 ; \mathrm{k}=0,1, \ldots, \mathrm{p}-1$

This is the principle of orthogonality Substituting Eq. (5) into Eq. (6)

$\mathrm{E}\left\{\mathrm{d}(\mathrm{n}) \mathrm{x}^{*}(\mathrm{n}-\mathrm{k})\right\}-$

$\sum_{\mathrm{l}=0}^{\mathrm{p}-1} \mathrm{w}(\mathrm{l}) \mathrm{E}\left\{\mathrm{x}(\mathrm{n}-\mathrm{l}) \mathrm{x}^{*}(\mathrm{n}-\right.$

$\mathrm{k})\}=0$

Finally, since $x(n)$ and $d(n)$ are alike Wide Sense Stationary then

$\mathrm{E}\left\{\mathrm{x}(\mathrm{n}-\mathrm{l}) \mathrm{x}^{*}(\mathrm{n}-\mathrm{k})\right\}=\mathrm{r}_{\mathrm{x}}(\mathrm{k}-\mathrm{l}) \quad$ and

$\mathrm{E}\left\{\mathrm{d}(\mathrm{n}) \mathrm{x}^{*}(\mathrm{n}-\mathrm{k})\right\}=\mathrm{r}_{\mathrm{dx}}(\mathrm{k})$ and

Eq. (7) becomes

$\sum_{\mathrm{l}=0}^{\mathrm{p}-1} \mathrm{w}(\mathrm{l}) \mathrm{r}_{\mathrm{x}}(\mathrm{k}-\mathrm{l})=\mathrm{r}_{\mathrm{dx}}(\mathrm{k}) \quad ;$

This is a set of $\mathrm{p}$ linear equations in the $\mathrm{p}$ unknowns $\mathrm{w}(\mathrm{k}), \mathrm{k}=0,1, \ldots, \mathrm{p}-1$. In matrix form, using the fact that the autocorrelation sequence is conjugate symmetric, $\mathrm{r}_{\mathrm{x}}(\mathrm{k})=$ $\mathrm{r}_{\mathrm{x}}^{*}(-\mathrm{k})$ Eq. (8) becomes

$\left[\begin{array}{cccc}r_{x}(0) & r_{x}^{*}(1) & \ldots \ldots r_{x}^{*}(p-1) \\ r_{x}(1) & r_{x}^{*}(0) & \ldots \ldots . r_{x}^{*}(p-2) \\ r_{x}(2) & r_{x}^{*}(1) & \ldots . . r_{x}^{*}(p-3) \\ & \vdots & & \\ & \cdot & & \\ r_{x}(p-1) & r_{x}^{*}(p-2) & \ldots \ldots \ldots . r_{x}^{*}(0)\end{array}\right]\left[\begin{array}{c}w(0) \\ w(1) \\ w(2) \\ \cdot \\ \cdot \\ \cdot \\ w(p-1)\end{array}\right]=$

$\left[\begin{array}{c}\mathrm{r}_{\mathrm{dx}}(0) \\ \mathrm{r}_{\mathrm{dx}}(1) \\ \mathrm{r}_{\mathrm{dx}}(2) \\ \cdot \\ \cdot \\ \mathrm{r}_{\mathrm{dx}}(\mathrm{p}-1)\end{array}\right]$

This is the matrix form of the Wiener-Hopf equations. Eq. (9) may be written more concisely as

$\mathrm{R}_{\mathrm{x}} \mathrm{W}=\mathrm{r}_{\mathrm{dx}}$ 
where $\mathrm{R}_{\mathrm{x}}$ is ap $\mathrm{x}$ pHermitianToeplitz matrix of autocorrelations, $w$ is the filter coefficients, and $r_{d x}$ is the vector of cross-correlations between the desired signal $d(n)$ may be evaluated from Eq. (3) as follows. With

$$
\begin{aligned}
& \xi=E\left\{|e(n)|^{2}\right\}=E\left\{e(n)\left[d(n)-\sum_{l=0}^{\mathrm{p}-1} w(l) x(n-l)\right]^{*}\right\}= \\
& E\left\{e(n) d^{*}(n)\right\}-\sum_{l=0}^{\mathrm{p}-1} \mathrm{w}^{*}(\mathrm{l}) \mathrm{E}\left\{\mathrm{e}(\mathrm{n}) \mathrm{x}^{*}(\mathrm{n}-\mathrm{l})\right\}
\end{aligned}
$$

Suppose the filter coefficient $\mathrm{w}(\mathrm{k})$ is given as the solution to the Wiener-Hopf equation, then it follows from Eq. (6) that $\mathrm{E}\left\{\mathrm{e}(\mathrm{n}) \mathrm{x}^{*}(\mathrm{n}-\mathrm{k})\right\}=0$. Therefore, the second term in Eq. (11) is equal to zero and

$$
\begin{aligned}
& \xi_{\min }=E\left\{e(n) d^{*}(n)\right\}=E\left\{\left[d(n)-\sum_{l=0}^{\mathrm{p}-1} w(l) x(n-\right.\right. \\
& \text { l) } \left.] d^{*}(n)\right\}
\end{aligned}
$$

Finally, taking expected values

$$
\xi_{\min }=\mathrm{r}_{\mathrm{d}}(0)-\sum_{\mathrm{l}=0}^{\mathrm{p}-1} \mathrm{w}(\mathrm{l}) \mathrm{r}_{\mathrm{dx}}^{*}(\mathrm{l})
$$

or, using vector notation,

$$
\xi_{\text {min }}=r_{d}(0)
$$

Alternatively, since

$$
\stackrel{w}{=} R_{x}^{-1} r_{d x}
$$

he minimum error may also be written explicitly in terms of the autocorrelation matrix $\mathrm{Rx}$ and the cross-correlation matrix rdx as follows:

$$
\xi_{\min }=r_{d}(0)-r_{d x}^{H} R_{x}^{-1} r_{d x}
$$

The Weiner filter is not suitable for non-stationary signal. For such a kind of situation the filter has to be timevarying and the solution for this is the Kalman filter.

\subsection{Evolution in Adaptive Filter}

R. Kalman [9] claimed that, the Kalman filter can be considered as extension of the Wiener filtering concept. The objective of Kalman filter is to minimize the least square error of a non-stationary signal corrupted with noise. In short, Kalman filtering deals with random processes described using state-space modelling. For a discrete non stationary finite dimensional process a link between the Wiener and Kalman theory has given by Nehorai et al [10]. The time varying realization and the relation between input and output is also explained. The authors have also described the state-space for nonstationary process and tried to explain Kalman gain with respect to Wiener theory.

A new filter based on "pontryasih minimum principle" has been described by Ahmed s et al. [11]. The best part of this method is; it eliminates the need to calculate many constant parameters. To update the coefficient of the filter the Saura Das Gupta [12] has given an option of a prediction error term. In this method, the adaptive algorithm was updated by a signum function just by manipulating the convergence rate for high order.

The concept of generalized multi delay filter was given by Eric Marlines [13]. This concept reduced the amount of time required for computation. For the case of infinite variance impulsive noise and non-Gaussian densities, Wiener filter theory is not meaningful. For non -Gaussian densities, zero forcing LMS is proven appropriate filter, which was designed by Bodenschatz and J.S.1[14].

Researcher K. C. Ho [15] has done the implementation of two adaptive filters in tandem. The paper has shown the implementation of convergence characteristics and tracking behaviour of two adaptive filters in tandem. K.C.Ho. has also shown a comparison of its performance with only one adaptive filter. The algorithm used was Least Mean Square and the parameters studied were mean square error, lag bias, and lag variance. It has been observed that, the tandem of two adaptive filter decreases the convergence speed as compared to a single adaptive filter with small step size.

Just a year after K. C Ho [16] given the concept of multiple LMS adaptive filters in tandem. The paper discussed about steady state error and its effect because of noise finding lag bias and variance. The Gaussian signal was taken as an input signal. For all those cases where the step size of filter is equal and small, the error due to noise grows linearly and the lag bias decays exponentially with the number of filters in tandem.

Li. Tan and Jean Jiang [17] designed a filter named as Volterra filter. It has been observed that noises comes from a dynamic system may be nonlinear and deterministic noise rather than a stochastic or white noise. Volterra filter based on a multichannel feed forward structure was able to overcome it. Undesirable effects of any instability that may arise in the filter can be avoided by addition of saturation

\begin{tabular}{|c|c|c|c|}
\hline Year & Author & Contribution & References \\
\hline 1949 & $\begin{array}{l}\text { Nobert } \\
\text { Wiener }\end{array}$ & $\begin{array}{l}\text { Design of wiener } \\
\text { filter }\end{array}$ & [1] \\
\hline 1950 & R.Kalman & $\begin{array}{l}\text { Design of Kalman } \\
\text { filter }\end{array}$ & [9] \\
\hline 1985 & Nehorai, A & $\begin{array}{c}\text { Link between } \\
\text { Kalman and } \\
\text { Wiener filter }\end{array}$ & [10] \\
\hline 1988 & Ahmend s & $\begin{array}{c}\text { Pontryasih } \\
\text { minimum } \\
\text { principle to design } \\
\text { a filter }\end{array}$ & [11] \\
\hline 1995 & $\begin{array}{c}\text { Eric } \\
\text { monlines }\end{array}$ & $\begin{array}{l}\text { Concept of multi } \\
\text { delay filter }\end{array}$ & [13] \\
\hline 2000 & К.С.Но & $\begin{array}{l}\text { Theory of two } \\
\text { adaptive filter in } \\
\text { tendom }\end{array}$ & [15] \\
\hline 2001 & K.C.Ho & $\begin{array}{l}\text { Theory of } \\
\text { multiple adaptive } \\
\text { filter in tendom }\end{array}$ & [16] \\
\hline 2001 & Li Tan & $\begin{array}{l}\text { Generation of } \\
\text { Volterra filter }\end{array}$ & [17] \\
\hline 2003 & H.K. Kwan & $\begin{array}{l}\text { Adaptive digital } \\
\text { IIR filter }\end{array}$ & [18] \\
\hline 2010 & Jingen Mi & $\begin{array}{l}\text { A variable Step } \\
\text { size matrix filter }\end{array}$ & [19] \\
\hline 2013 & Smital & $\begin{array}{c}\text { Adaptive Wavelet } \\
\text { Wiener Filtering }\end{array}$ & [20] \\
\hline
\end{tabular}
operation at the output [18].A variable step size adaptive filter has also been designed by Jingen $\mathrm{Mi}$ et al [19].Recently the Wiener filter has been implemented using wavelet transform by Smital et al [20]. The goal of the author was to get a perfect filter bank and find all parameters of wiener filter in terms of SNR. Concluding this section, Table I has shown the revolution done during past years.

Table I. Revolutionary Years for Adaptive filter generation 


\section{Adaptive Filter Structure}

The adaptive filter realization is divided into two parts, The FIR (Finite Impulse Response) filter and IIR (Infinite Impulse Response) filter. The most common and most popular finite impulse response adaptive filter is transversal filter. This is all zero transfer function filter. This filter implemented with direct form without feedback as in this case the output of this filter is a linear combination of its coefficient.

The adaptive infinite impulse response adaptive filter can also realize with direct form. It is a recursive filter so there are so many problems associated with it. It converges slowly; depends on the filter structure and need some criterion to monitor the stability of poles. To overcome all these problems, other options like cascade, lattice, and parallel realizations are available. The analysis and implementation for the use of non-canonical FIR filters has done by Stewart, R.W and Soraghan, J.J.[21]. They have shown that for all gradient based algorithm the noncanonical filter is not a good choice. So it is important to reformulate the classical adaptive algorithm and reanalysed for parameters like convergence and stability.

But it has been shown by authors Gan, W.S. et al. [22] that, non-canonical FIR structure, performed better in terms of reduced excess mean square error level, faster convergence even with an abrupt noise environment. But at the same time it will be important to take care of step size and nonstationary characteristics of non-canonical structure.

Researcher Kwan, H.K. and Li, Q.P [23] proposed, delayed N-path structures for high-speed adaptive linear phase FIR and IIR digital filtering. The resulting throughput rate of the designed system using N-path structure reaches 2N2 times then the old adaptive finite impulse response digital filter. Result obtained was high speed structure for adaptive noise cancellation. This filter with cascade structure updated with gradient algorithm [24] shows slow adaption to find the value of error. To overcome the disadvantage of first order cascade FIR structure, team of researcher Prandoni et al [25] has given a second-order cascade LMS filters. This design was able to model most input signals, with smaller mean square error than least mean square or lattice least mean square.

Many structure of IIR realisation has also been implemented. A modified cascade structure for IIR adaptive algorithm was introduced by authors R.A. David et.al. [26]. J.J.Shynk [27]. They have also presented several parallel form adaptive IIR filters that included a frequency domain implementation based recursive frequency sampling structure. In order to improve the performance of IIR based systems several modified structure had been introduced such as improved parallel realization of infinite impulse response adaptive filters based on frequency domain approach. The frequency domain implementation led to increased convergence rates and lower computational complexity [28].

Lattice structure stability can be achieved during the adaptation process by D. Parikh, N. Ahmed, and S. D. Stearns [29]. A new adaptive lattice structure was proposed by I. L. Ayala [30], lattice form algorithms for adaptive IIR by J. J. Shynk and group [31],new normalized lattice algorithm by M. Tummala [32], Gradient calculation in adaptive IIR lattice filters by J. A. Rodr' [33] and fast parallel realization for IIR by P. S. R. Diniz et al [34].One recursive nonlinear state space filter has also been designed by Gao, F.X.Y et al [35].Those kinds of filters comes in picture when there is a need of extended memories. This structure will be useful to reduce computation for gradients and useful for real time signal processing.

Tabus, I. [36] proposed a gradient based maximization routine to IIR filter with best parameters. IIR filters outperforms with same parameters with good gain then FIR filter. Later a hybrid model of FIR/IIR adaptive filter was introduced by Pasquato, L. [37], with the aim to deflate main problem of adaptive IIR filter.

To detect and estimate the frequency of sinusoids with Gaussian noises, a new second-order lattice form structure of adaptive infinite impulse response (IIR) notch filter was proposed by Hong, Liang et al [38]. This was done by utilizing least square kurtosis of output signals as a cost function; the new gradient-based algorithm updates the frequency of the adaptive IIR notch filter. Table II has shown revolutionary time during past years for the FIR and IIR structure.

Table 2. Revolutionary Concepts Given in the Field of FIR/IIR Structure

\begin{tabular}{|c|c|c|c|}
\hline Year & Author & Contribution & References \\
\hline 1989 & M. L. & $\begin{array}{l}\text { Non Canonical } \\
\text { Filter Structure } \\
\text { for FIR }\end{array}$ & [20] \\
\hline 1993 & Kwan, H.K. & $\begin{array}{l}\text { Delayed N-Path } \\
\text { Structure for FIR }\end{array}$ & [23] \\
\hline 1994 & Forssen U & $\begin{array}{c}\text { Cascade } \\
\text { Structure } 1^{\text {st }} \\
\text { order for FIR }\end{array}$ & [24] \\
\hline 1998 & Prandoni, $\mathrm{P}$ & $\begin{array}{c}\text { Cascade } \\
\text { Structure } 2^{\text {nd }} \\
\text { order for FIR }\end{array}$ & [25] \\
\hline 1981 & R. A. David & $\begin{array}{c}\text { Cascade } \\
\text { Structure for IIR }\end{array}$ & [26] \\
\hline 1989 & J. J. Shynk & $\begin{array}{l}\text { Parallel structure } \\
\text { for IIR }\end{array}$ & [27] \\
\hline 1991 & $\begin{array}{c}\text { J. A. } \\
\text { Rodr'1guez- } \\
\text { Fonollosa }\end{array}$ & $\begin{array}{l}\text { Lattice Structure } \\
\text { for IIR }\end{array}$ & [33] \\
\hline 1994 & Gao, F.X.Y & $\begin{array}{l}\text { Recursive state } \\
\text { space filter for } \\
\text { IIR }\end{array}$ & [35] \\
\hline 2001 & Pasquato, L & $\begin{array}{l}\text { hybrid FIR/IIR } \\
\text { adaptive filter } \\
\text { combination }\end{array}$ & [37] \\
\hline 2009 & Hong, Liang & $\begin{array}{c}\text { Lattice structure } \\
\text { for IIR notch } \\
\text { filter }\end{array}$ & {$[38]$} \\
\hline
\end{tabular}

\section{The Adaptive Algorithm}

After adaptive filter and structure, to update the coefficient of adaptive filter; adaptive algorithm is required. The aim of adaptive algorithm is to adjust the weights of adaptive filters tap vectors to minimize the error. To choose the particular adaptive algorithm its computational complexity has to be taken care of. The tap weights of a filter can be updated using Wiener-Hopf equation. The main attraction of adaptive 
algorithm is, it can starts from any initial points and slowly move towards the main point. There are so many search algorithms those were derived to minimize the cost function real statistics. The most common algorithm used is Least
Mean Square (LMS) algorithm. This algorithm is a part of steepest decent method, which requires an estimation of the gradient signal at each iteration.

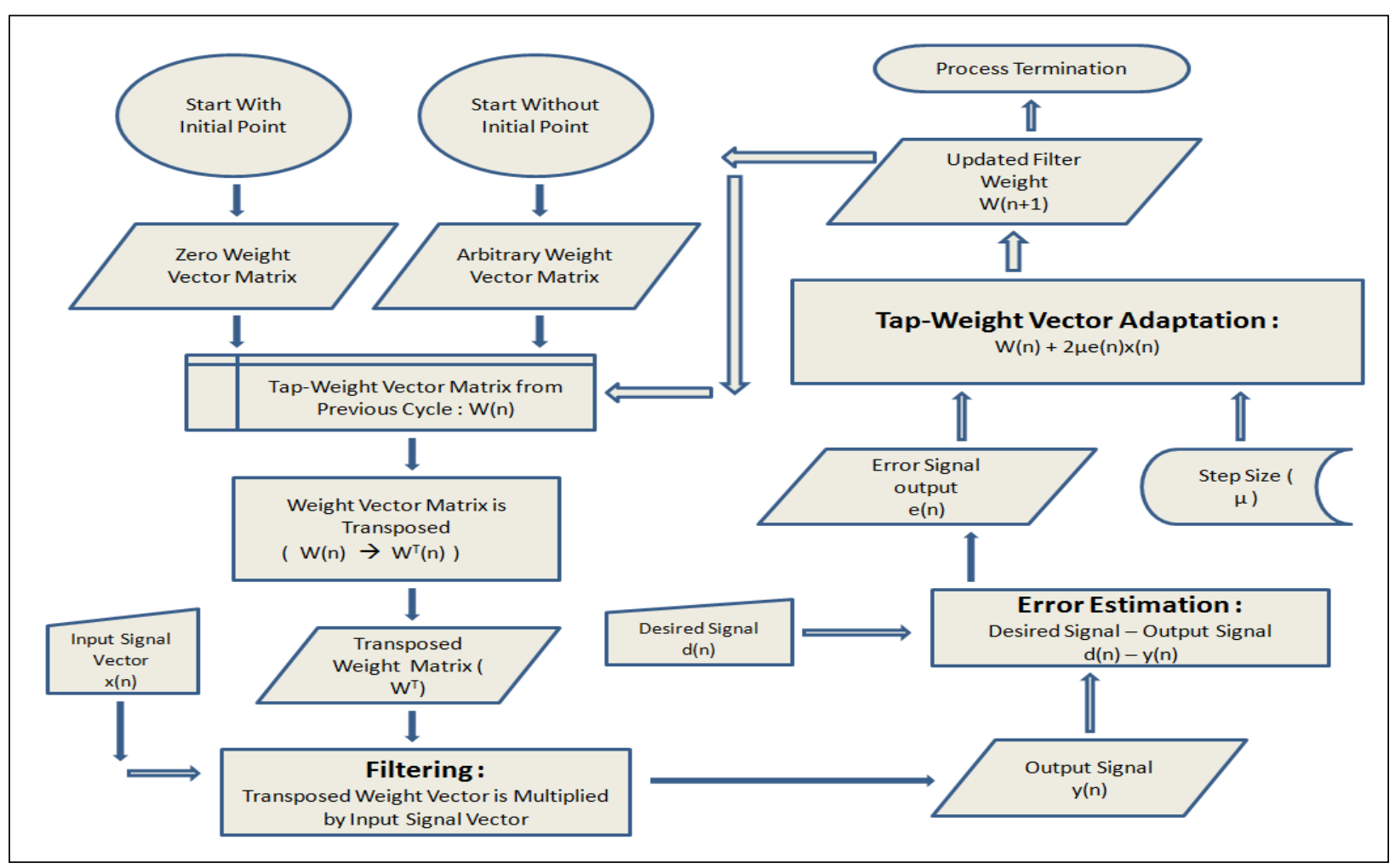

Fig. 2. Flow chart for LMS algorithm

Table 3. Basic Parameters for LMS algorithm

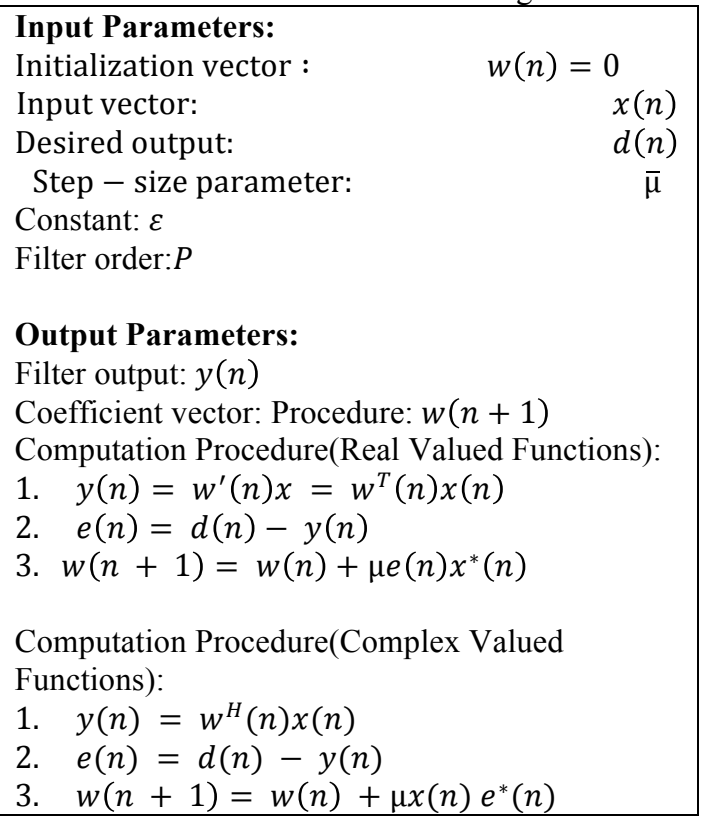

The LMS (Least Mean Square) algorithm was introduced by B.Widrow and M. E. Hoff [39]. LMS algorithm estimates the gradient vector from available data. LMS is an iterative procedure that makes successive corrections to the weight vector. This is done in the direction of negative of the gradient vector which in course of time leads to minimum mean square error. Flow chart of the algorithm is shown in Fig 2.

Table III shows input, output parameter, step size notation and the equation using which weights has to be updated. The adaptive filter using steepest descent has tap weight vector equation given by

$\mathrm{w}_{\mathrm{n}+1}=\mathrm{w}_{\mathrm{n}}+\mu \mathrm{E}\left\{\mathrm{e}(\mathrm{n}) \mathrm{x}^{*}(\mathrm{n})\right\}$

There is a practical limitation with this algorithm is that the expectation $\mathrm{E}\left\{\mathrm{e}(\mathrm{n}) \mathrm{x}^{*}(\mathrm{n})\right\}$ is not known. So it was replaced by taking estimated sample mean.

$$
\widehat{\mathrm{E}}\left\{\mathrm{e}(\mathrm{n}) \mathrm{x}^{*}(\mathrm{n})\right\}=\frac{1}{\mathrm{~L}} \sum_{\mathrm{i}=0}^{\mathrm{L}-1} \mathrm{e}(\mathrm{n}-\mathrm{l}) \mathrm{x}^{*}(\mathrm{n}-\mathrm{l})
$$

Combining this estimate with the steepest descent algorithm, updated equation for $\mathrm{w}_{\mathrm{n}}$ becomes

$\mathrm{w}_{\mathrm{n}+1}=\mathrm{w}_{\mathrm{n}}+\frac{\mu}{\mathrm{L}} \sum_{\mathrm{i}=0}^{\mathrm{L}-1} \mathrm{e}(\mathrm{n}-\mathrm{l}) \mathrm{x}^{*}(\mathrm{n}-\mathrm{l})$

A special case of above equation occurs if it use a one point sample mean $(\mathrm{L}=1)$,

$\widehat{\mathrm{E}}\left\{\mathrm{e}(\mathrm{n}) \mathrm{x}^{*}(\mathrm{n})\right\}=\mathrm{e}(\mathrm{n}) \mathrm{x}^{*}(\mathrm{n})$

The update equation to weight update assumes a simple form and is known as LMS algorithm. 
$\mathrm{w}_{\mathrm{n}+1}=\mathrm{w}_{\mathrm{n}} \mu \mathrm{e}(\mathrm{n}) \mathrm{x}^{*}(\mathrm{n})$

It is simple because it can update for kth coefficient that requires only one multiplication and one addition.

$\mathrm{w}_{\mathrm{n}+1}(\mathrm{k})=\mathrm{w}_{\mathrm{n}}(\mathrm{k})+\mu \mathrm{e}(\mathrm{n}) \mathrm{x}^{*}(\mathrm{n}-\mathrm{k})$

And because of that an adaptive filter based on LMS having $p+1$ coefficient require $2 p+3$ multiplications and $2 p+2$ additions per output value [40]. The advantages of LMS are, its simplicity and numerical stability. The limitation are its slow convergence and may not respond well in nonstationary environment

In last case, weight vector matrix consists of arbitrary weight. The tap weight from the previous cycle is $\mathrm{W}(\mathrm{n})$, and weight vector matrix transposed is $\mathrm{W}^{\mathrm{T}}(\mathrm{n})$. The transposed weight matrix $\left(\mathrm{W}^{\mathrm{T}}(\mathrm{n})\right)$ is multiplied with the input signal vector $x(n)$ through filtering and giving the output signal $y(n)$. This is followed by error estimation which is obtained as desired signal d(n) minus, output signal $y(n)$. The error signal output $e(n)$ together with step size $\mu$ is used for tap weight vector adaptation $x(n)+2 \mu e(n) x(n)$. The filter weight is updated and process is followed recursively till it terminates [41].

LMS algorithm based on the method of steepest decent search method and was conditionally stable. The researcher Frank F. et al [42] presented a modified LMS algorithm, which was unconditionally stable and achieve same mean steady state weight as LMS. Modified LMS (MLMS) can apply to noise cancellation filters for the case of ideal and leaky integration. The modified LMS algorithm is used for stationary input.

For nonstationary input signals the statistical efficiency of LMS algorithm was given by B. Widrow. Then limiting behaviour of LMS algorithm was given by Victor solo [43]. The idea was to control excess mean square error. The reason to control excess mean square error was gradient noise misadjustment and lag misadjustment performance. It has been seen that the classical lag misadjustment formula had missing additional noise misadjustment and variance terms. That formula is completed by William A. [44] and proved that for local experimental stability, persistence of excitation criterion is required.

It is also important to reduce weight function by high variance data so there is a need of new non gradient algorithm that can reduce adaptive filter weight fluctuations. This algorithm should adapt a single weight at each time step and should be given same computational requirement as the LMS algorithm. J Thomos [45] has given an algorithm named as SWIM (Single Weight Iteration Method). This algorithm used non gradient search techniques. The advantages of SWIM algorithm are: very fast convergence, low computational requirement, minimum weight fluctuations, guaranteed convergence, and is not affected by the input signal with large variance. SWIM has also carries some drawbacks like, misadjustment, Excess error, rate of convergence, stability criterion, effectiveness on different type of data input.

A nonlinear analytical model for adaptive algorithm was proposed by Neil J Bershad et al [46]. They have shown the quantization effect of LMS algorithm with the power of two step size. Later analysis of real Fourier transform based adaptive algorithm has been done and tested with the Hartley transform using cosine-sine symmetries by Vasanthan Raghvan et. al [47].

Concluding this section, LMS algorithm is the most popular used algorithm in adaptive filtering. The important features that force everyone to use LMS algorithm are; good convergence in stationary environment, stable behaviour, low computational; complexity and finite precision arithmetic. This section concludes using Table IV shown below. It shows years those contribute with adaptive algorithm or given new concepts about the adaptive algorithm for adaptive noise cancellation.

\subsection{Variants of Adaptive Algorithms}

This section will discuss all those algorithms implemented using adaptive filters and are derived from conventional LMS algorithm. The objective behind deriving other algorithms than LMS is to reduce computational complexity or convergence time.

Table 4. Revolutionary Years for LMS Algorithm for Noise Cancellation

\begin{tabular}{l|l|l|l}
\hline Year & Author & Contribution & References \\
\hline 1960 & $\begin{array}{l}\text { B.Widrow } \\
\text { and M. E. } \\
\text { Hoff } \\
\text { Frank F. }\end{array}$ & $\begin{array}{l}\text { LMS has been } \\
\text { introduced } \\
\text { Modified LMS } \\
\text { has been } \\
\text { introduced } \\
\text { SWIM has been } \\
\text { generated } \\
\text { Failure time } \\
\text { analysis of LMS } \\
\text { Low complexity } \\
\text { data-reusing } \\
\text { method } \\
\text { A novel LMS } \\
\text { algorithm }\end{array}$ & {$[46]$} \\
\hline J. Thomos & $\begin{array}{l}\text { Adel A. } \\
\text { Zerai } \\
\text { R. A. Soni }\end{array}$ \\
\hline
\end{tabular}

An extended approach to reduce computational complexity of LMS algorithm was done by W.A. Sethares and C. R. Johnson [48]. They have shown the persistence of excitation condition, which guarantees linear stability of the quantized error form. The quantized-error algorithm reduces the computational complexity of LMS algorithm. This theory is given by E. Eweda, J. C. M. Bermudez et al and W.A. Sethares et al [49-51] through the error signal with short word length or by a simple power-oftwo number. B.widrow and S.D. Steanrns [52] implemented LMS-Newton algorithm. They worked on the convergence speed of algorithm which was independent of the eigen value of the input signal correlation matrix. This is done by finding the estimated value of the inverse of input signal correlation matrix. But it leads to ample increase in the computational complexity [53].

There is another side of the LMS algorithm too which needs to improve is; its implementation in time domain. The LMS algorithm implemented for noise cancellation in frequency domain and time domain is compared by Francis A reed et al [54]. The result revealed greater amount of reduction in computation complexity then the time domain with white noise input. The frequency domain algorithm was implemented using FFT. In frequency domain, it is also 
possible to find mean and variance of the tap weights of adaptive filters.

It was concluded by M. Dentno et al, S. S. Narayan et al, D. F. Marshall, [55-57] that the filtering in the transform domain results great output in terms of convergence speed due to less computational complexity than the time domain filtering. They have used DFT (Discrete Fourier Transform) and DCT (Discreet cosine Transform) adaptive filtering algorithm especially for speech signal processing. But there are two problems found by J. C. Lee, C. K. Un, N.J. Bershad , P.L. Fleintech, S.Shankar Narayan and A.M. Pelusi, [58-60], one as the order of the filer increases its step size decreases and results slow algorithm. Second problem is, the input signal of the highly correlated filter results large spread of eigen values of autocorrelation matrix which causes algorithm to slow down again.

The failure time analysis for LMS algorithms shown by Abel A et al [61]. A system failure may depend upon the occurrence of a large error and clumps of large errors. Poisson approximation has been used to study failure of the LMS algorithm in time domain and its three signed variants. For fast convergence affine projection algorithm has been described by K. Ozeki and T. Umeda [62]. Its faster version was given by S. L. Gay el at [63]. How faster convergence impacted the applications, was described by researcher S. G. Sankaran and A. A.

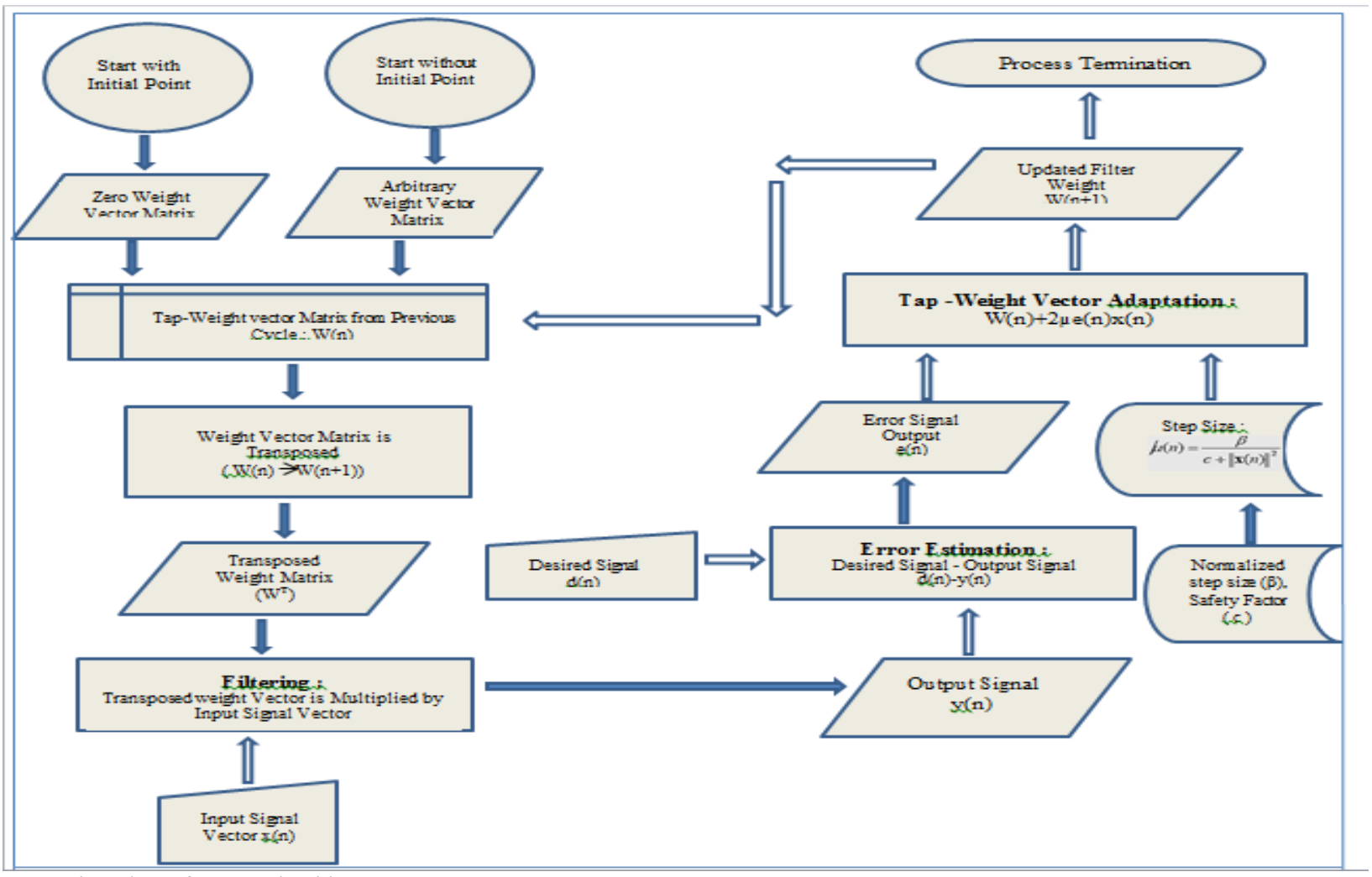

Fig 3. Flow chart of NLMS algorithm

Beex [64]. It has also been seen that if the input signal is extremely correlated then there is always a trade-off between the convergence speed and computational complexity [6568].

The effects of the power level estimate are incorporated in a data depends upon $\mu$ that appears explicitly within algorithm is proved by N.J Bershad and andIrvine [69]. Authors were also evaluated the transient mean and secondmoment behaviour of the modified LMS (NLMS) algorithm. It was evaluated by taking into account that explicit statistical dependence upon $\mu$ of the input data. Keeping all these points in mind the NLMS (Normalised Least Mean Square) algorithm introduced by F. F. Yassa [70]. This algorithm increased the convergence speed of LMS algorithm without using the estimates of the input signal correlation matrix. Here the basic parameters used for the NLMS shown.

NLMS were derived from the part of nonlinear stochastic gradient LMS algorithm. This is done by choosing normalized time varying step size parameter. This parameter reduces the next step that reduces mean square error after every iteration. Now to improve the convergence rate, a variable convergence factor uk has been employed. The equation become

$\mathrm{w}(\mathrm{k}+1)=\mathrm{w}(\mathrm{k})+2 \mu \mathrm{ke}(\mathrm{k}) \mathrm{x}(\mathrm{k})=\mathrm{w}(\mathrm{k})+\Delta^{\sim} \mathrm{w}(\mathrm{k})$

Table 5. Basic Parameters of NLMS

\section{Input parameters: \\ Initialization vector: $w(n)=0$,}

Input vector: $x(n)$, Desired output: $d(n)$

Step - size parameter: $\bar{\mu}$, Constant: $\varepsilon$, Filter order: $P$

\section{Output Parameters:}

Filter output: $y(n)$, Coefficient vector: Procedure: $w(n+1)$

Computation Procedure (Real Valued Functions):

1. $y(n)=w^{\prime}(n) x=w(n) \mathrm{x}^{\mathrm{T}}(n)$

2. $e(n)=d(n)-y(n)$

3. $w(n+1)=w(n)+\frac{\bar{\mu}}{\varepsilon+x^{T}(n) x(n)} e(n) x(n)$

Computation Procedure (Complex Valued Functions): 
1. $y(n)=w^{H}(n) x(n)$

2. $e(n)=d(n)-y(n)$

3. $w(n+1)=w(n) \frac{\bar{\mu}}{\varepsilon+x^{H}(n) x(n)} x(n) e^{*}(n)$

Where $\mu \mathrm{k}$ must be chosen to achieve faster convergence and to reduce the instantaneous squared error as much as possible.

A priori knowledge of stability and convergence of the LMS adaptive filter algorithm requires the input power level to select the algorithm gain parameter $\mu$. Since the input power level is usually one of the statistical parameter unknowns, it is normally estimated from the data received prior to beginning the adaptation process. Consider LMS recursion algorithm

$\mathrm{w}(\mathrm{n}+1)=\mathrm{w}(\mathrm{n})+2 \mu(\mathrm{n}) \mathrm{e}(\mathrm{n}) \mathrm{x}(\mathrm{n})$

where step-size parameter varies in time. It has been observed that the filter length and power of the signal is highly influenced, convergence, stability and steady state behaviour of LMS algorithm. So

$\mu(\mathrm{n})=\frac{1}{2 \mathrm{x}^{\mathrm{T}}(\mathrm{n}) \mathrm{x}(\mathrm{n})}=\frac{1}{2\|\mathrm{x}(\mathrm{n})\|^{2}}$

$\mathrm{F}$

rom above equation to find the recursion

$w(n+1)=w(n)+\frac{1}{x^{T}(n) x(n)} e(n) x(n)$

The above equation is using a posteriori error minimization. Hence,

$w(n+1)=w(n)+\frac{\bar{\mu}}{\varepsilon+x^{T}(n) x(n)} e(n) x(n)$

Where $\bar{\mu}$ and $\varepsilon$ are constants. Study of the first and secondorder behavior of Normalized Least Mean Square (NLMS) algorithm has been introduced by M. Tarrab and A. Feuer [71]. The LMS design was based on the statistics of input signal so a new design was presented by D. T. Slock [72]. This model analysed the NLMS and LMS algorithm for their convergence behaviour. Then S.C.Douglas and T.H.Y. Meng [73] proposed a nonlinear LMS algorithm where statistics parameters analysed were based on memory less nonlinearities.

A new NLMS algorithm was given by Emilio et al [74] .This new algorithm shows easy demonstration of the optimum value of adaptive constant in the LMS algorithm. This algorithm uses a value for the adaption constant that assure the fastest convergence. It also minimizes the MSE of the adaptive systems which is based on a simple Taylor's expansion. Author S. kalluri [75] obtained a general nonlinear NLMS type algorithm by choosing flawless time varying step size that minimizes the next step mean square error after every iteration of the nonlinear LMS algorithm.

To control echo from speech signals a modified LMS algorithm has been analysed by J.Ensor and A. Lewis [76]. The results proved that the algorithm provide uniform speech band cancellation and lower misadjustment than LMS algorithm at same convergence rate with additional mathematics.

A new method based on posterior estimation has been defined by J. M. Górriz [77], where error was defined by the minimization of Euclidean distance between weight vectors. This provides all inclusive comparison between almost all adaptive algorithms like LMS, Modified LMS (M-LMS), Error Nonlinearity (EN-LMS) etc.The advantages of NLMS are; faster convergence, automatic time varying choice of the LMS step size parameter; steady state mean square error and good convergence speed of the algorithm.

To adapt individual filter parameters, individual convergence factors have been proposed by W.B. Mikhel [78]. The author has also worked on to adjust the convergence factors of individual parameter in real time. R.W.Harris [79] has used a technique; where for each weight of an adaptive filter with transversal realization carries a feedback constant. This is a new way for the implementation of LMS algorithm.

LMS algorithm is in demand because of its simplicity, robustness and best tracking capability. But there is always has a compromise with step size and misadjustment. As the step size increases stability decreases and as it decreases stability increases. Jeronimo A. G has shown in his paper [80] that the filter weights depends on the spectra of input signals and additive noise and step size. This problem is overcome by Z.Shengkui[81] by combining many LMS filter with different steps. Using this method the combination of step size and misadjustment provides the better tracking capability for each weight to speed them up.

A variable step size (VSS) LMS algorithm introduced by Ting Lieu and Saeed Gazar[82] to assist the process of conflicting requirement. The large step size needed for fast convergence and small step size needed for misadjustment factor. Then a new algorithm for variable step size algorithms has been designed by Leonardo Rey [83] as robust Variable Step Size NLMS algorithm. This algorithm was based on the optimization of cost time dependent function to update the filter coefficient. This optimizes the square of the posterior error. A theoretical model for predicting the transient and steady-state behaviour has given and a proof of almost sure filter convergence were provided.

To improve the weakness of lastly developed variable step-size least mean- square (VSLMS) algorithm a new VSLMS has been proposed by Jeng-Kuang Hwang [84]. The algorithm was gradient based and took the average of the weights. The specific application found using this algorithm for colour input environment or system identification. Numerous variable step-size normalized least mean-square (VSS-NLMS) algorithms have been derived to solve the crisis of fast convergence rate or low excess meansquare error in the past two decades. Hsu et al in their paper [85], proposed a new, easy to implement, nonparametric VSS-NLMS algorithm that make use of meansquare error and the estimated system noise power to control the step-size update. This section is concluded using Table VI

Table 6. Revolutionary TimefFor Variants of LMS Algorithm

\begin{tabular}{l|l|l|l}
\hline Year & Author & Contribution & References \\
\hline 1986 & F. F. Yassa & NLMS introduced & {$[69]$} \\
\cline { 3 - 4 } 2002 & $\begin{array}{l}\text { Ting Lieu } \\
\text { and Saeed } \\
\text { Gazar }\end{array}$ & $\begin{array}{l}\text { Variable step size } \\
\text { pre-filter bank } \\
\text { algorithm }\end{array}$ & {$[82]$} \\
\cline { 3 - 4 }
\end{tabular}




\begin{tabular}{l|l|l|l}
\cline { 3 - 3 } 2005 & Jeronimo A & $\begin{array}{l}\text { Algorithm for } \\
\text { convex } \\
\text { combination of } \\
\text { LMS transversal } \\
\text { filter }\end{array}$ & {$[80]$} \\
\cline { 3 - 4 } 2006 & Z. Shengkui & $\begin{array}{l}\text { Modified LMS } \\
\text { and NLMS with } \\
\text { Variable Step Size }\end{array}$ & {$[81]$} \\
\cline { 3 - 4 } & $\begin{array}{l}\text { VSS-NLMS } \\
\text { algorithm }\end{array}$ & {$[85]$} \\
\hline
\end{tabular}

\subsection{LMS verses RLS (Recursive Least Square)}

There is another side of the coin too, which deals with the fast transversal RLS (Recursive Least Square) algorithms. But this algorithm has stability problems in practical implementation.

The objectives of LMS (Least mean squares) algorithms are minimization of sum of the squares of difference between the desired signal and model filter output [86]. Recursive least-squares (RLS) algorithms given the solution of the problem when new samples of incoming signals are received at each iteration [87-88]. The Recursive Least Square (RLS) algorithms are known to accompany fast convergence even when the eigen value spread of the input signal correlation matrix is large. These algorithms have excellent performance when working in time-varying environments [89-90]. All these advantages come with the cost of an increased computational complexity and some stability problems, which are not as critical in LMS-based algorithms.

Concluding this section, so many modified adaptive filtering algorithms has been discussed, those basically advanced version of LMS. There are two ways to categorized them, first category keeps all those algorithm having simpler algorithm with less computational complexity and other category is concern about the advance and improved performance of existing algorithm. The simpler algorithm provides least complexity in implementation with the increasing cost of misadjustment and low convergence speed. The advanced and improved algorithms provide more computational complexity.

\section{Conclusion}

The presented paper has reviewed 50 years of adaptive filter, their structure, adaptive algorithm mainly Least Mean Square (LMS) and one of its variant Normalised Least Mean Square (NLMS). Considerable emphasis has been given to work reported in the development of Adaptive noise cancellation system.

This is an Open Access article distributed under the terms of the Creative Commons Attribution Licence

\section{References}

[1] N. Wiener, Extrapolation, Interpolation and Smoothing of Stationary Time Series, with Engineering Applications. New York: Wiley, 1949.

[2] B.Widrow, J. R. Grover, Jr., J. M. McCool, J. Kaunitz, C. S.Williams, R. H. Hearns, J. R. Zeidler, E. Dong, Jr., and R. C. Goodlin, "Adaptive noise cancelling: Principles and applications, "Proceedings of the IEEE, vol. 63, pp. 1692-1716, Dec. 1975.

[3] B.Widrow and S. D. Stearns, Adaptive Signal Processing, Prentice Hall, Englewood Cliffs, NJ,1985.

[4] S. T. Alexander, Adaptive Signal Processing, Springer Verlag, NewYork, NY, 1986.

[5] J. R. Treichler, C. R. Johnson, Jr., and M. G. Larimore, Theory and Design of Adaptive Filters, JohnWiley \& Sons, NewYork, NY, 1987.

[6]M. Bellanger, Adaptive Digital Filters and Signal Analysis, Marcel Dekker, Inc., New York, NY, 2nd Edition, 2001.

[7]S. Haykin, Adaptive Filter Theory, Prentice Hall, Englewood Cliffs, NJ, 4th edition, 2002.

[8] A. H. Sayed, Fundamentals of Adaptive Filtering, JohnWiley \& Sons, Hoboken, NJ, 2003

[9] R. Kalman, "On the general theory of control," in Proc. 1st pp. $417-$ 425, Apr. 1950.

[10] Nehorai, A., Palo Alto, Morf, M. "A mapping result between Wiener theory and Kalman filtering for nonstationary processes" Automatic Control, IEEE Transactions on (Volume:30, Issue: 2 ), pp. 175 - 177, February 1985.

[11] Ahmend s., Abutakb, “An Adaptive Filter for Noise Cancellation ", IEEE Transactions on Circuit and Systems, Vol. 35, No. 10, pp 1205-1219, Oct 1988 .

[12] Saura Das Gupta,Jetters., Grarnett and C. Richard; "Convergence of an adaptive filter with signed filter error", IEEE Transactions on Signal Processing, Vol. 42, No. 4, pp. 946-949, April 1994.

[13] Eric monlines, Omar Aif Amrane and Yues Gremier, "The generalized multidelay adaptive filter: Structure and convergence analysis", IEEE Transactions on Signal processing, Vol. 43, No. 1, pp. 14-28, Jan 1995.
[14] Bodenschatz, J.S. ; Dept. of Electr. Eng., Univ. of Southern California, Los Angeles, CA, USA ; Nikias, C.L." Symmetric alpha-stable filter theory", Signal Processing, IEEE Transactions on Vol.45, Issue: 9 , pp. $2301-2306$, Sep 1997.

[15] K.C. Ho, "A study of two adaptive filters in Tandem", IEEE Transactions on Signal processing, Vol. 48, No. 6, pp. 1626-1636, June 2000.

[16] K.C. Ho, "Performance of multiple LMS Adaptive Filter in Tandem", IEEE Transactions on Signal processing, Vol. 49, No.11, pp. 2762-2771, Nov 2011

[17] Li Tan, Jean Jiang, "Adaptive Volterra filters for active Control of nonlinear processes", IEEE Transactions on Signal processing, Vol. 49, No. 8, pp. 1667-1674, Aug 2001.

[18] H.K. Kwan, "Adaptive digital IIR filter with saturation output for noise and echo cancellation", Electronic Letters, Vol. 38, No. 13, pp. 13-24, , June 2003.

[19] Jingen Ni, Feng Li, "A Variable Step Size Matrix Normalised sub band adaptive filter," IEEE Transactions on Audio, Speech and language processing, Vol.18, Issue: 6 ,pp. $1290-1299,2010$.

[20] Smital, L. Vítek, M. ; Kozumplík, J. ; Provazník, I., "Adaptive Wavelet Wiener Filtering of ECG Signals", IEEE Transactions on Biomedical Engineering, Vol.60, Issue: 2 ,pp. $437-445$, Feb. 2013.

[21] Stewart, R.W. ; Strathclyde Univ., UK ; Soraghan, J.J. ; "Noncanonical FIR filters and adaptive signal processing" Electronics Letters, Vol.25, Issue: 6 pp. 414 - 415, March 1989.

[22] Soraghan, J.J. ; Stewart, R.W. ; Durrani, T.S., Dept. of Electr. \& Eletron. Eng., Strathclyde Univ., Glasgow, UK ; Electronics Letters," Comparative analysis between non-canonical LMS and LMS adaptive filtering "Vol.27, Issue: 11, pp. 947 - 950, 23 May 1991.

[23] Kwan, H.K. ; Li, Q.P. "High-speed realisation of adaptive linear phase FIR digital filters, "Radar and Signal Processing, IEE Proceedings, Vol.40, Issue: 1, pp. 48 - 54 Feb 1993.

[24] Forssen U., "Analysis of adaptive FIR filters in cascade form", IEEE Transaction of Circuits and Systems II: Analog and Digital Signal Processing, Vol. 41, Issue: 6, pp.392 - 401, Jun 1994. 
[25] Prandoni, P. ; Ecole Polytech. Fed. de Lausanne, Switzerland ; Vetterli,M., " An FIR cascade structure for adaptive linear prediction", on Signal Processing, IEEE Transactions Vol.46 , Issue: 9,pp: 2566 - 2571, Sep 1998.

[26] R. A. David, "A modified cascade structure for IIR adaptive algorithms," Proc. 15th Asilomar Conf. on Circuits, Systems, and Computers, Pacific Grove, CA, pp. 175-179, Nov. 1981.

[27] J. J. Shynk, "Adaptive IIR filtering using parallel-form realization," IEEE Trans. on Acoust., Speech, and Signal Processing, vol. 37, pp. 519-533, April 1989.

[28] P. S. R. Diniz, J. E. Cousseau, and A. Antoniou, "Improved parallel realization of IIR adaptive filters," Proceedings of the IEE Part G: Circuits, Devices, and Systems, vol. 140, pp. 322-328, Oct. 1993.

[29] D. Parikh, N. Ahmed, and S. D. Stearns, "An adaptive lattice algorithm for recursive filters," IEEE Trans. on Acoust., Speech, and Signal Processing, vol. ASSP-28, pp. 110-112, Feb. 1980.

[30] I. L. Ayala, "On a new adaptive lattice algorithm for recursive filters," IEEE Trans. on Acoust., Speech, and Signal Processing, vol. ASSP-30, pp. 316-319, April 1982.

[31] J. J. Shynk, "On lattice-form algorithms for adaptive IIR filtering," Proc. IEEE Intern. Conf. On Acoust., Speech, Signal Processing, NewYork, NY, pp. 1554-1557, April 1988.

[32] M. Tummala, "New adaptive normalized lattice algorithm for recursive filters," Electronics Letters, vol. 24, pp. 659-661, May 1988.

[33] J. A. Rodr'1guez-Fonollosa and E. Masgrau, "Simplified gradient calculation in adaptive IIR lattice filters," IEEE Trans. on Signal Processing, vol. 39, pp. 1702-1705, July 1991.

[34] P. S. R. Diniz, J. E. Cousseau, and A. Antoniou, "Fast parallel realization for IIR adaptive filters," IEEE Trans. on Circuits and Systems-II: Analog and Digital Signal Processing, vol. 41, pp. 561-567, Aug. 1994.

[35] Gao, F.X.Y.; Snelgrove, W.M. "Adaptive nonlinear recursive state-space filters" IEEE Transactions on Circuits and Systems II: Analog and Digital Signal Processing, Volume:41, Issue: 11, pp 760 - 764, Nov 1994.

[36] Tabus, I. ; “A design procedure for optimal energy compaction IIR filters", Signal Process. Lab., Tampere Univ. of Technol., Finland ; Corneliu Popeea ; Astola, Circuits and Systems II: Analog and Digital Signal Processing, IEEE Transactions, Vol.48, Issue: 7, pp. $740-744$, Jul 2001.

[37] Pasquato, L. ; Dept. of Electron. Syst., Univ. of Westminster, London, UK ; Kale, "Adaptive IIR filter initialization via hybrid FIR/IIR adaptive filter combination ", Instrumentation and Measurement, IEEE Transactions, Vol.50, Issue: 6, pp 1830 1835, Dec 2001.

[38] Hong, Liang ; Coll. of Marine, Northwestern Polytechnical Univ., Xi'an 710072, P. R. China ; Kang, Hong ; Changsheng, Yang "Lattice structure adaptive IIR notch filter based on least square kurtosis", Journal of Systems Engineering and Electronics, Vol.20, Issue: 6,pp 1188-1192, Dec. 2009.

[39] B.Widrow and M. E. Hoff, "Adaptive Switching Circuits", WESCOM Conv., pt 4. pp 96-140, 1960.

[40] B. Widrow, J. R. Glover, J. M. Mccool, J. Kaunitz, C. S. Williams, R.H. Hean, J. R. Zeidler, E. Dong, and R. C. Goodlin, "Adaptive noise cancelling: Principles and applications," Proc. IEEE, vol. 63, no. 12, pp. 1692-1716, Dec. 1975.

[41] Frank F, “An Improve Algorithm for Adaptive Processing”, IEEE Transaction on Aerospace and Electronic System, Vol 14, No 1, pp. 172-177, Jan 1978.

[42]Widrow,B. ; Walach,E.,"On the statistical efficiency of the LMS alg orithm with non-stationary inputs" IEEE Transaction of Signal Processing Vol. 30 , Issue: 2 , pp. $211-221,1984$.

[43] Victor solo, "The Limiting Behaviour of LMS", IEEE Transaction on Acoustic, Speech and Signal Processing, Vol. 37, No 12, pp. 1909-1922, Dec 1989

[44] William A "Adaptive algorithm with nonlinear data and error function", IEEE Transaction on Signal Processing, Vol. 40, No. 9, pp. 2199-2206, Sep 1992.

[45] J Thomos, Cilke and Delones M. Etler " A new Adaptive algorithm to reduce weight fluctuation caused by high variance data with nonlinear data and error function", IEEE Transaction on Signal Processing, Vol. 40, No. 9, pp. 2324-2327, Sep 1992.

[46] Neil J Bershad and Jose C.M.B. "A nonlinear analytical model for Quantized LMS algorithm: The power of two Step Size", IEEE Transaction on Signal Processing, Vol. 44, No.11, pp. 2895-2900, Nov 1999.
[47] Vasanthan Raghvan, K. M.M. Prabhu and Piet C.W. , "An Analysis of Real Fourier Domain based Adaptive Algorithm Implemented with the Hartley Transform using cosine- sine Symmetries", IEEE Transaction on Signal Processing, Vol. 53, No.2, pp. 622-629, Feb 2005.

[48] W.A. Sethares and C. R. Johnson, Jr., "A comparison of two quantized state adaptive algorithms," IEEE Trans. on Acoust., Speech, and Signal Processing, Vol. ASSP-37, pp. 138-143, Jan. 1989.

[49] E. Eweda, "Convergence analysis and design of an adaptive filter with finite-bit power-of-two quantize error," IEEE Trans. on Circuits and Systems II: Analog and Digital Signal Processing, Vol. 39, pp. 113-115, Feb. 1992.

[50] J. C. M. Bermudez and N. J. Bershad, "A nonlinear analytical model for the quantized LMS algorithm: The arbitrary step size case," IEEE Trans. on Signal Processing, Vol. 44, pp. 1175-1183, May 1996.

[51] W.A. Sethares and C. R. Johnson, Jr., "A comparison of two quantized state adaptive algorithms," IEEE Trans. on Acoust., Speech, and Signal Processing, Vol. ASSP-37, pp. 138-143, Jan. 1989.

[52] B.Widrow and S. D. Stearns, Adaptive Signal Processing, Prentice Hall, Englewood Cliffs, NJ,1985.

[53] P. S. R. Diniz and L.W. Biscainho, "Optimal variable step size for the LMS/Newton algorithm with application to subband adaptive filtering," IEEE Trans. on Signal Processing, vol. SP-40, pp. 2825 2829, Nov. 1992.

[54] Francis A Reed and paul L Freintach, "A comparison of LMS Adaptive canceller Implemented in the frequency domain nad the time domain," Trans. On Circuits and Systems, Vol CAS-28, No 6,pp. 610-615, June 1981.

[55] M. Dentno, Jone Mccool and B. Wodrow, "Adaptive filtering in frequency domain," proceeding letters, pp 1658-1660, 1978.

[56] S. S. Narayan, A. M. Peterson, and M. J. Narasimha, "Transform domain LMS algorithm," IEEE Trans. on Acoust., Speech, and Signal Processing, vol. ASSP-31, pp. 609-615, June 1983.

[57] D. F. Marshall,W. K. Jenkins, and J. J. Murphy, "The use of orthogonal transform for improving performance of adaptive filters, " IEEE Trans. on Circuits and Systems, vol. 36, pp. 474484, April 1989.

[58] J. C. Lee and C. K. Un, "Performance of transform-domain LMS adaptive digital filters," IEEE Trans. on Acoust., Speech, and Signal Processing, vol. ASSP-34, pp. 499-510, June 1986.

[59] N.J. Bershad and P.L. Fleintech, "Analysis of frequency domain adaptive filter", Proceedings of IEEE, Vo.1 67, No. 12, pp. 16581660, Dec 1979

[60] S.Shankar Narayan and A.M. Pelusi, "Frequency Domain LMS Algorithm", Proceedings of IEEE, Vol. 69, No 1, pages 124-127, Jan 1981.

[61] Adel A. Zerai, Member, IEEE, and James A. Bucklew, Senior Member, IEEE, "Failure Time Analysis for LMS Algorithms", IEEE Transactions On Information Theory, Vol. 48, No. 4, pp 918-932, April 2002.

[62] K. Ozeki and T. Umeda, "An adaptive filtering algorithm using an orthogonal projection to an affine subspace and its properties," Electronics and Communications in Japan, vol. 67-A, pp. 19-27, 1984.

[63] S. L. Gay and S. Tavathia, "The fast affine projection algorithm," Proc. IEEE Int. Conf. On Acoust., Speech, and Signal Processing, Detroit, MI, pp. 3023-3026, May 1995.

[64] S. G. Sankaran and A. A. (Louis) Beex, "Convergence behavior of affine projection algorithms," IEEE Trans. on Signal Processing, vol. 48, pp. 1086-1096, April 2000.

[65] J. A. Apolin'ario, M. L. R. de Campos, and P. S. R. Diniz, "The binormalized data-reusing LMS algorithm," IEEE Trans. on Signal Processing, vol. 48, pp. 3235-3242, Nov. 2000.

[66] R. A. Soni, K. A. Gallivan, and W. K. Jenkins, "Low-complexity data-reusing methods in adaptive filtering," IEEE Trans. on Signal Processing, vol. 52, pp. 394-405, Feb. 2004.

[67] S.Werner and P. S. R. Diniz, "Set-membership affine projection algorithm," IEEE Signal Processing Letters, vol. 8, pp. 231-235, Aug 2001.

[68] G.-O. Glentis, K. Berberidis, and S. Theodoridis, "Efficient least squares adaptive algorithms for FIR transversal filtering," IEEE Signal Processing Magazine, vol. 16, pp. 13-41, July 1999.

[69] F. F. Yassa, "Optimality in the choice of convergence factor for gradient based adaptive algorithms," IEEE Trans. on Acoust., 
Speech, and Signal Processing, vol. ASSP-35, pp. 48-59, Jan. 1987.

[70]Bershad,N.J. andIrvine," Analysis of the normalized LMS algorithm with Gaussian inputs" , Acoustics, Speech and Signal Processing, IEEE Transactions on Volume:34, Issue: 4, pp. 793 -806, Aug 1986.

[71] M. Tarrab and A. Feuer, "Convergence and performance analysis of the normalized LMS algorithm with uncorrelated Gaussian data," IEEE Trans. on Information Theory, vol. IT-34, pp. 680691, July 1988.

[72] D. T. Slock, "On the convergence behaviour of the LMS and normalized LMS algorithms," IEEE Trans. on Signal Processing, vol. 40, pp. 2811-2825, Sept. 1993.

[73] S. C. Douglas and T. H. Y. Meng, "Normalized data nonlinearities for LMS adaptation," IEEE Trans. Signal Process. vol. 42, no. 6, pp.1352-1354, Jun. 1994.

[74] Emilio Soria Olives, J Calpe, Juan F, M.M. Sober and Jose ,’An easy demonstration of the optimum value of the adaption constant in the LMS algorithm,'IEEE Transaction on Education,Vol. 41, No.1,pp. 81-82, Feb 1998.

[75] S . Kalluri, Gonzalo R., “A General Class of Nonlinear Normalized Adaptive Filtering Algorithms," IEEE Transaction on Signal Processing, Vol 47, No 8, pp. 2262-2272, August 1999.

[76] J. Ensor and A. Lewis ,"N2LMS: Enhanced LMS algorithm for speech applications " ELECTRONICS LETERS, Vol. 35 No. 10, May 1999.

[77] J. M. Górriz, Javier Ramírez, S. Cruces-Alvarez, Carlos G. Puntonet, Elmar W. Lang, and DenizErdogmus, "A Novel LMS Algorithm Applied to Adaptive Noise Cancellation”, IEEE Signal Processing Letters, Vol. 16, No. 1, January 2009.

[78] W. B. Mikhael, F. H. Fu, L. G. Kazovsky, G. S. Kang, and L. J. Fransen, "Adaptive filter with individual adaptation of parameters," IEEE Trans. on Circuits and Systems, vol. 33, pp. 677-686, July 1986.

[79] R.W. Harris, D. M. Chabries, and F. A. Bishop, “A variable step (VS) adaptive filter algorithm," IEEE Trans. on Acoust., Speech, and Signal Processing, vol. ASSP-34, pp. 309-316, April 1986.
[80] Jeronimo A. G., V. G. Verdejo and Anibar, "New algorithms for Improved Adaptive Convex Combination of LMS Transversal Filters," IEEE Transaction on Instrumentation and Measurement, Vol. 54, No.6, pp. 2239-2846, Dec 2005.

[81] Z. Shengkui, M. Zhihong, K. Suiyang," Modified LMS and NLMS Algorithms with a New Variable Step Size" Proc IEEE, 2006.

[82] Ting Lieu and Saeed Gazar "A variable step size pre filter bank adaptive algorithm", IEEE Transaction on Speech and Audio Processing, Vol. 13, No.5, pp. 905-916, Sep 2005.

[83] Leonardo Rey Vega, Hernán Rey, Jacob Benesty, Senior Member, IEEE, and Sara Tressens, "A New Robust Variable Step-Size NLMS Algorithm”, IEEE Transactions On Signal Processing, Vol. 56, No. 5,pp. 1878-1889, May 2008.

[84] Jeng-Kuang Hwang, Member, IEEE, and Yuan-Ping Li, "Variable Step-Size LMS Algorithm With a Gradient-Based Weighted Average", IEEE Signal Processing Letters, Vol. 16, No. 12, pp.1043-1047, December 2009.

[85] Hsu-Chang Huang ; Dept. of Electr. Eng., Yuan-Ze Univ., Chungli, Taiwan ; Junghsi Lee, "A New Variable Step-Size NLMS Algorithm and Its Performance Analysis", Signal Processing, IEEE Transactions on, Vol.60 , Issue: 4, pp. 2055 - 2060 , April 2012.

[86] Diniz P., Adaptive Filtering algorithm and its practical Implementation, Springer, 3rd edition 2008.

[87] G. C. Goodwin and R. L. Payne, Dynamic System Identification: Experiment Design and Data Analysis, Academic Press, NewYork, NY, 1977.

[88] S. Haykin, Adaptive Filter Theory, Prentice Hall, Englewood Cliffs, NJ, 4th edition, 2002

[89] S. H. Ardalan, "Floating-point analysis of recursive least-squares and least-mean squares adaptive filters," IEEE Trans. on Circuits and Systems, vol. CAS-33, pp. 1192-1208, Dec. 1986.

[90] J. M. Cioffi, "Limited precision effects in adaptive filtering," IEEE Trans. on Circuits and Systems, vol. CAS-34, pp. 821-833, July 1987. 